\title{
HUBUNGAN SISTEM PERENCANAAN DENGAN PENGANGGARAN DALAM PENDIDIKAN
}

Fatkhul Mubin

fatkhulmubin90@gmail.com

\begin{abstract}
Abstraksi
Tulisan ini disusun oleh pemakalah dengan tujuan untuk menjelaskan tentang Hubungan Sistem Perencanaan Dengan Penganggaran Dalam Pendidikan. Penulisan ini menggunakan metode kualitatif. Hasil penelitian ini menyimpulkan bahwa system perencanaan dan penganggaran sangat berkaitan. Dengan perencanaan anggaran yang baik, tentu dapat mengarahkan pada tujuan pendidikan yang dikehendaki bersama.
\end{abstract}

Kata Kunci : Penganggaran, Pendidikan

\section{PENDAHULUAN}

Biaya pendidikan merupakan salah satu komponen masukan instrumental (instrumental) yang sangat penting dalam penyelenggaraan pendidikan (di sekolah). Dalam setiap upaya pencapaian tujuan pendidikan, baik tujuan-tujuan yang bersifat kuantitatif maupun kualitatif, biaya pendidikan memiliki peranan yang sangat menentukan.

Hampir tidak ada upaya pendidikan yang dapat mengabaikan peranan biaya, sehingga dapat dikatakan bahwa tanpa biaya, proses pendidikan (di sekolah) tidak akan berjalan. Biaya (cost) dalam pengertian ini memiliki cakupan yang luas, yakni semua jenis pengeluaran yang berkenaan dengan penyelenggaraan pendidikan, baik dalam bentuk uang maupun barang dan tenaga (yang dapat dihargakan dengan uang). ${ }^{1}$

\footnotetext{
1 Saihu, S. (2019). RINTISAN PERADABAN PROFETIK UMAT MANUSIA MELALUI PERISTIWA TURUNNYA ADAM AS KE-DUNIA. Mumtaz: Jurnal Studi Al-Quran dan Keislaman, 3(2), 268-279,

Saihu, S. (2019). Pendidikan Pluralisme Agama: Kajian tentang Integrasi Budaya dan Agama dalam Menyelesaikan Konflik Sosial Kontemporer. Jurnal Indo-Islamika, 9(1), 67-90,

Saihu, S. (2019). IMPLEMENTASI MANAJEMEN BALANCED SCORECARD DI PONDOK PESANTREN JAM'IYYAH ISLAMIYYAH TANGERANG SELATAN. Mumtaz: Jurnal Studi Al-Quran dan Keislaman, 3(1), 122.

Saihu, S. (2019). KOMUNIKASI PENDIDIK TERHADAP ANAK BERKEBUTUHAN KHUSUS DI SEKOLAH KHUSUS ASY-SYIFA LARANGAN. Andragogi: Jurnal Pendidikan Islam dan Manajemen Pendidikan Islam, 1(3), 418-440.
} 
Di samping itu, dikenal juga anggaran belanja pendidikan (education budget) yang terdiri atas dua komponen, yaitu pendapatan, pemasukan atau penerimaan di satu pihak dan pengeluaran atau belanja. Dalam sistem anggaran di indonesia alokasi biaya rutin kepada lembaga-lembaga atau satuan-satuan penyelenggara pendidikan dituangkan dalam DIK (daftar isian kegiatan), sedangkan biaya pembangunan dialokasikan dalam DIP (daftar isian proyek). Di samping itu dikenal pula DIKS (daftar isian kegiatan suplemen) yaitu, alokasi anggaran yang sumber dananya berasal dari masyarakat. ${ }^{2}$

Pada tingkat provinsi dan kabupaten/kota, anggaran untuk sektor pendidikan sebagian besar berasal dari dana yang diturunkan dari pemerintah pusat ditambah dengan pendapatan asli daerah (PAD) yang dituangkan dalam rencana anggaran pendapatan dan belanja daerah (RAPBD).

Saihu, S., \& Marsiti, M. (2019). PENDIDIKAN KARAKTER DALAM UPAYA MENANGKAL RADIKALISME DI SMA NEGERI 3 KOTA DEPOK, JAWA BARAT. Andragogi: Jurnal Pendidikan Islam dan Manajemen Pendidikan Islam, 1(1), 23-54.

Saihu, S. (2019). KONSEP MANUSIA DAN IMPLEMENTASINYA DALAM PERUMUSAN TUJUAN PENDIDIKAN ISLAM MENURUT MURTADHA MUTHAHHARI. Andragogi: Jurnal Pendidikan Islam dan Manajemen Pendidikan Islam, 1(2), 197-217.

Saihu, S., \& Rohman, B. (2019). PEMBENTUKAN KARAKTER MELALUI MODEL PENDIDIKAN TRANSFROMATIFE LEARNING PADA SANTRI DI PONDOK PESANTREN NURUL IKHLAS BALI. Edukasi Islami: Jurnal Pendidikan Islam, 8(02), 435-452.

${ }^{2}$ Saihu, S., \& Taufik, T. (2019). PERLINDUNGAN HUKUM BAGI GURU. Al Amin: Jurnal Kajian Ilmu dan Budaya Islam, 2(2), 105-116.

Saihu, S. (2020). KONSEP PEMBAHARUAN PENDIDIKAN ISLAM MENURUT FAZLURRAHMAN. Andragogi: Jurnal Pendidikan Islam dan Manajemen Pendidikan Islam, 2(1), 82-95.

Saihu, S. (2020). ETIKA MENUNTUT ILMU MENURUT KITAB TA'LIM MUTA'ALIM. Al Amin: Jurnal Kajian Ilmu dan Budaya Islam, 3(1), 99-112.

Saihu, Aziz, A., Mubin, F., \& Sarnoto, A. Z. (2020). Design of islamic education based on local wisdom (An analysis of social learning theories in forming character through ngejot tradition in bali). International Journal of Advanced Science and Technology, 29(6), 1278-1293.

Ronaldo, R., Zulfikar, A., Saihu, Ismail, \& Wekke, I. S. (2020). International relations of the asia pacific in the age of trump. Journal of Environmental Treatment Techniques, 8(1), 244-246.

Saihu, M. M., \& Aziz, A. (2020). Implementasi Metode Pendidikan Pluralisme Dalam Mata Pelajaran Pendidikan Agama Islam. Belajea; Jurnal Pendidikan Islam, 5(1), 131-150.

Saihu, M. (2019). Urgensi 'Urf dalam Tradisi Male dan Relevansinya dalam Dakwah Islam di JembranaBali. Jurnal Bimas Islam, 12(1), 173-201.

Saihu, S. (2020). The Effect of Using Talking Stick Learning Model on Student Learning Outcomes in Islamic Primary School of Jamiatul Khair, Ciledug Tangerang. Tarbawi: Jurnal Keilmuan Manajemen Pendidikan, 6(01), 61-68.

Saihu, S. (2020). Pendidikan sosial yang terkandung dalam Surat At-Taubah Ayat 71-72. Edukasi Islami: Jurnal Pendidikan Islam, 9(01), 127-148. 
Fragmentasi anggaran maksudnya ialah untuk kegitatan yang hampir sama atau untuk jenjang pendidikan yang sama, anggaran tersebar di beberapa departemen. Prosesnya melibatkan biro perencanaan departemen, Bappenas, dan departemen keuangan. ${ }^{3}$

\section{PEMBAHASAN}

\section{A. Pengertian perencanaan anggaran lembaga pendidikan}

Dalam buku landasan manajemen pendidikan, menurut koonts penganggaran (budgetting) merupakan satu langkah perencanaan yang fundamental. Anggaran dapat diartikan sebagai suatu rencana operasi dari suatu kegiatan atau proyek yang mengandung perincian pengeluaran biaya untuk suatu periode tertentu. ${ }^{4}$

Keuangan dan pembiayaan merupakan salah satu sumber daya yang secara langsung menunjang efektifitas dan efisiensi pengelolaan pendidikan. Hal tersebut lebih terasa lagi dalam implementasi manajemen berbasis sekolah. Yang menuntut kemampuan sekolah untuk merencanakan, melaksanakan, dan mengevaluasi serta mempertanggungjawabkan pengeloaan data secara transparan kepada masyarakat dan pemerintah.

Dalam penyelenggaraan pendidikan, keuangan dan pembiayaan merupakan potensi yang sangat menentukan dan merupakan bagian yang tidak terpisahkan dalam kajian perencanaan pendidikan. Komponen keuangan dan pebiayaan dalam suatu lembaga pendidikan merupakan komponen produksi yang menentukan terlaksanakannya kegiatan-kegiatan dalam proses pelaksanaan lembaga pendidikan, artinya setiap program yang akan di laksanakan pasti membutuhkan dan memerlukan anggaran lembaga yaitu biaya keuangan. Sehingga anggaran lembaga yaitu komponen keuangan dan pembiayaan perlu dikelola sebaik-baiknya. Agar anggaran lembaga yang ada dapat dimanfaatkan secara optimal untuk menunjang tercapainya pendidikan. ${ }^{5}$

\footnotetext{
${ }^{3}$ Dedi Supriadi, Satuan Biaya Pendidikan, PT. Remaja Rosdakarya, Bandung, 2004, hlm. 3-9

${ }^{4}$ Nanang Fattah, Landasan Manajemen Pendidikan, PT Remaja Rosdakarya, Bandung, 1996, hlm. 68

5 Aziz, A., \& Saihu, S. (2019). Interpretasi Humanistik Kebahasaan: Upaya Kontekstualisasi Kaidah Bahasa Arab. Arabiyatuna: Jurnal Bahasa Arab, 3(2), 299-214

Saihu, S. (2019). PENDIDIKAN KARAKTER BERBASIS KEARIFAN LOKAL (STUDI DI JEMBRANA BALI). Edukasi Islami: Jurnal Pendidikan Islam, 8(01), 69-90.

Şahin, C. RELIGIA.

Saihu, S., \& Mailana, A. (2019). Teori pendidikan behavioristik pembentukan karakter masyarakat muslim dalam tradisi Ngejot di Bali. Ta'dibuna: Jurnal Pendidikan Islam, 8(2), 163-176.

Mubin, F. KEADILAN DALAM GENDER: KAJIAN KEPEMIMPINAN WANITA DALAM ISLAM1,

Saihu, M. (2019). Merawat Pluralisme Merawat Indonesia (Potret Pendidikan Pluralisme Agama Di JembranaBali). Deepublish.
} 
Sumber keuangan dan pembiayaan pada suatu lembaga pendidikan, dapat dikelompokkan dalam tiga sumber, yaitu:

1) Pemerintah, baik pemerintah pusat dan pemerintah daerah, baik yang bersifat umum dan khusus dan diperuntukkan dalam lembaga pendidikan.

2) Orang tua atau peserta didik.

3) Masyarakat.

Biaya yang dikeluarkan dalam suatu anggaran lembaga pendidikan antara lain yaitu biaya rutin adalah biaya yang dikeluarkan dari tahun ketahun, seperti gaji guru, pegawai dalam lembaga pendidikan, biaya operasional, biaya pemeliharaan gedung, fasilitas, alat-alat pengajaran,,biaya pembangunan gedung, dan lain sebagainya.

Anggaran lembaga dalam komponen keuangan harus dilaksanakan denagn baik dan teliti, dari tahap penyusunan anggaran, penggunaan, pengawasan, sesuai dengan aturan dan ketentuan yang berlaku, agar semua anaggaran dapat di manfaatkan secara efektif, efisien, serta bebas dari korupsi. ${ }^{6}$

Menurut jones dalam buku manajemen berbasis sekolah karya Dr. E Mulyasa, M.P.d menjelaskan bahwa tugas pengelola anggaran lembaga dibagi dalam tiga fase antara lain financial planning, implementation dan evaluation. Komponen utama dalam mengelola anggaran meliputi:

1. prosedur anggaran,

2. prosedur akutansi keuangan,

3. pembelanjaan,

4. prosedur investasi

5. prosedur pemeriksaan $^{7}$

Persoalan penting dalam penganggaran yaitu bagaimana pemanfaatan sumber-sumber secara efisien. Itulah sebabnya penganggaran memerlukan proses yang bertahap. Tahap-tahap yang perlu dilakukan sebagai berikut:

a. Mengidentifikasi kegiatan yang akan dilaksanakan dalam periode anggaran.

\footnotetext{
Mubin, F. (2019). TAFSIR EMANSIPATORIS: PEMBUMIAN METODOLOGI TAFSIR PEMBEBASAN. Mumtaz: Jurnal Studi Al-Quran dan Keislaman, 3(1), 131-151. Mubin, F. MODEL-MODEL PEMBELAJARAN BERBASIS MADRASAH DAN KEGIATAN LAIN YANG DIPERLUKAN DI DALAMNYA (FAKTOR PENDUKUNGNYA).

${ }^{6}$ E. Mulyasa, Manajemen berbasis sekolah, PT Remaja Rosdakarya, Bandung, Mei 2004. hlm 47-48

${ }^{7}$ Ibid, hlm 49
} 
b. Mengidentifikasi sumber-sumber yang dinyatakan dalam uang, mesin dan material.

c. Sumber-sumber dinyatakan dalam bentuk uang, sebab anggaran pada dasarnya merupakan pernyataan finansial.

d. Memformulasikan anggaran menurut format yang telah disepakati.

e. Usaha memperoleh persetujuan dari yang berwenang (pengambilan keputusan) dalam tahap ini dilakukankompromi melalui rapat-rapat untuk mempertimbangkan secara objektif dan subjektif.

Dalam mendesain budget terdapat bentuk:

a. Penganggaran butir per butir.

Bentuk penganggaran ini memudahkan kontrol pengeluaran biaya, tetapi tidak membantu untuk pengambilan keputusan.

b. Program budget

Bentuk ini menekankan pada sasaran-sasaran konkret dinyatakan dalam pernyataan fungsional. Oleh karena itu, penganggaran berdasarkan program mengharuskan diadakan pemilihan sasaran dan alokasi sumber berdasarkan analisis sistematik.

Perencanaan bertujuan, menjembatani jurang antara apa yang ada sekarang dengan yang diinginkan pada masa depan. Perbedaan antara keadaan sekarang dan masa depan ini memberikan bahan untuk perencanaan dalam menetapkan tujuan yang hendak dicapai dibidang pendidikan. Itulah sebabnya, perencanaan pendidikan sebagai kegiatan yang kompleks sesuai dengan kompleksitasnya masalah pendidikan.

Demikian pula penganggaran diperlukan sebagai formulasi rencana dalam pengertian uang, berfungsi memanfaatkan sumber-sumber secara efisien, dapat dijadikan alat pengawasan dan penilaian sampai beberapa jauh tingkat efektivitas dan efisiensi kegiatan tercapai. ${ }^{8}$

\section{B. Hal-hal yang terkait dalam perencanaan anggaran lembaga pendidikan}

a) Penyusunan anggaran

Dalam kaitannya dengan proses penyusunan anggaran, dalam buku Manajemen pendidikan, Lipham mengungkapkan 4 fase kegiatan pokok sebagai berikut:

1) Merencanakan anggaran.

\footnotetext{
${ }^{8}$ Nanang Fattah, Op.Cit, hlm. 68-69
} 
2) Mempersiapkan anggaran.

3) Mengelola pelaksanaan anggaran.

4) Menilai pelaksanaan anggaran.

\section{b) Proses anggaran belanja sekolah}

Ada tiga macam pendekatan tentang penyusunan anggaran belanja yang biasa dipergunakan di sekolah.

\section{Comparative approach}

1) Melakukan perbandingan laporan atau catatan penerimaan dengan pengeluaran antara satu tahun anggaran dengan tahun anggaran berikutnya.

2) Dalam keputusan anggaran belanja ini didasarkan pada peningkatan tambahan dari satu hal pada waktunya ke hal yang lain.

2. The planning programming budgeting evaluating system approach

1) Menjabarkan tujuan kedalam program-program ke dalam sarana-sarana khusus.

2) Menjabarkan nilai dari masing-masing alternatif.

3) Menjabarkan biaya pelaksanaan dan evaluasi masing-masing program.

\section{Function approach}

- Proses anggaran dimulai dari tujuan sekolah.

- Termasuk dalam pendekatan ini adalah elemen-elemen yang terkandung dalam pendekatan comperative dan PPBES. ${ }^{9}$

Penganggaran merupakan kegiatan atau proses penyusunan anggaran (bubget). Budget merupakan rencana operasional yang dinyatakan secara kuantitatif dalam bentuk satuan uang yang digunakan sebagai pedoman dalam melaksanakan kegiatankegiatan lembaga dalam kurun waktu tertentu. Oleh karena itu, dalam anggaran tergambar kegiatan-kegiatan yang akan dilaksanakan oleh suatu lembaga.

Penyusunan anggaran merupakan langkah-langkah positif untuk merealisasikan rencana yang telah disusun. Kegiatan ini melibatkan pimpinan tiap-tiap unit organisasi. Pada dasarnya penyusunan anggaran merupakan negosiasi atau perundingan/kesepakatan antara puncak pimpinan dengan pimpinan di bawahnya dalam menentukan besarnya alokasi biaya suatu penganggaran. Hasil akhir dari suatu

\footnotetext{
${ }^{9}$ Fatah Syukur, Manajemen Pendidikan, PT. Pustaka Rizki Putra, Semarang, 2011, hlm. 114-116
} 
negosiasi merupakan suatu pernyataan tentang pengeluaran dan pendapatan yang diharapkan dari setiap sumber data. ${ }^{10}$

\section{c) Karakteristik anggaran}

Anggaran pada dasarnya terdiri dari dua sisi, yaitu sisi penerimaan dan sisi pengeluaran. Sisi penerimaan atau perolehan biaya ditentukan oleh besarnya dana yang diterima oleh lembaga dari setiap sumber dana. Biasanya dalam pembahasan pembiayaan pendidikan, sumber-sumber biaya itu dibedakan dalam tiap golongan, pemerintah, masyarakat, orang tua dan sumber-sumber lain. Sisi pengeluaran terdiri dari seluruh penerimaan biaya, sebagian dipergunakan untum mebiayai kegiatan administrasi, ketatausahaan, sarana dan prasarana pendidikan dll. ${ }^{11}$

\section{d) Fungsi anggaran}

Anggaran disamping sebagai alat untuk perencanaandan pengendalian, juga merupakan alat bantu bagi manajemen dalam mengarahkan suatu lembaga menempatkan organisasi dalam posisi yang kuat dan lemah. Oleh karena itu, anggraan juga dapat berfungsi sebagai tolak ukur keberhasilan suatu organisasi dalam mencapai sasaran yang telah ditetapkan. Di samping itu, anggaran dapat pula dijadikan alat untuk mempengaruhi dan memotivasi pimpinan atau manajer dan karyawan untuk bertindak efisien dalam mencapai sasaran-sasaran lembaga.

- Anggaran juga berfungsi sebagai alat perencanaan, yang antara lain digunakan untuk:
a) Merumuskan tujuan serta sasaran kebijakan sesuai dengan visi dan misi yang ditetapkan.
b) Merencanakan berbagai program dan kegiatan untuk mencapai tujuan organisasi serta merencanakan alternatif sumber pembiayaan.
c) Mengalokasikan sumber-sumber anggaran pada berbagai program dan kegiatan yang telah disusun.
d) Menentukan indikator kinerja dan tingkat pencapaian strategi.

- Anggaran berfungsi sebagai alat pengendalian, yang digunakan antara lain:

a) Mengendalikan efisiensi pengeluaran

\footnotetext{
${ }^{10}$ Nanang Fattah, “Ekonomi Dan Pembiayaan Pendidikan”, Rosdakarya, Bandung, 2004,hlm. 47

${ }^{11}$ Ibid, hlm. 48
} 
b) Membatasi kekuasaan dan wewenagan lembaga pendidikan

c) Mencegah adanya overspending dan salah sasaran dalam mengalokasiskan anggaran dalam suatu lembaga pendidikan.

d) Memonitor kondisi keuangan dan peraksanaan operasional program lembaga pendidikan.

- Anggaran sebagai alat kebijakan fiskal digunakan untuk menstabilkan anggaran lembaga dan mondorong kemanjuan dalam kegiatan lembaga pendidikan.

- Anggaran sebagai alat koordinasi antar unit kerja dalam penyusunan anggaran.

- Anggaran dapat digunakan sebagai alat evaluasi kinerja.

- Anggran dapat digunakan sebagai alat untuk memotivasi manajemen pendidikan agar bekerja secara ekonomi, efektif dan efesien.

- Anggaran dapat juga sebagai alat untuk menciptakan ruang public, artinya semua jaringan dalam hal pendidikan dapat membarikan manfaat kepada semua bidang pendidikan. ${ }^{12}$

\section{e) Prinsip-prinsip anggaran}

Prinsip-prinsip anggaran sebagai berikut:

a. Adanya pembagian wewenang dan tanggung jawab yang jelas dalam system manajemen dan organisasi.

b. Adanya system akuntasi yang memadai dalam melaksanakan anggaran.

c. Adanya penelitian dan analisis untuk menilai kinerja organisasi.

d. Adanya dukungan dari pelaksana mulai dari tingkat atas sampai yang paling bawah.

Persoalan penting dalam penyusunan anggaran adalah bagaimana memanfaatkan dana secara efisisn, mengalokasikan secara tepat, sesuai dengan skala priorit. ${ }^{13}$

\section{f) Pengawasan anggaran}

Konsep dasar tentang pengawasan anggaran bertujuan untuk mengukur, membandingkan, menilai alokasi biaya dan tingkat penggunaannya. Dengan kata lain, pengawasan angaran diharapkan dapat mengetahui sampai di mana tingkat efektivitas dan efisiensi dari penggunaan sumber-sumber dana yang tersedia.

\footnotetext{
${ }^{12}$ Udin Syaifudin Sa'ud Dan Abin Syamsuddin Makmun. Perencanaan Pendidikan Suatu Pendekatan Komprensif, Bandung: PT Remaja Rosdakarya. 2007, hlm 261-263

${ }^{13}$ Nanang Fattah, Op.Cit, hlm. 49-50 
Prinsip pengawasan:

1) System pengawasan fungsional yang dimulai sejak perencanaan yang menyangkut aspek penilaian, kehematan, efisiensi, efektivitas ynag mencakup seluruh aktivitas program di setiap bidang organisasi.

2) Hasil temuan pengawasan harus ditindak lanjuti dengan koordinasi antara aparat pengawasan dengan aparat penegak hokum serta instansi terkait turut menyamakan persepsi, mencari pemecahan bersama atas masalah yang dihadapi.

3) Kegiatan pengawasan hendaknya lebih diarahkan pada bidang yang strategis dan memperhatikan aspek manajemen.

4) Kegiatan pengawasan hendaknya member dampak terhadap penyeleksian masalah dengan konsepsional dan menyeluruh.

5) Kegiatan pengawasan dilakukan oleh orang-orang yang memiliki kompetensi teknis, sikap, dedikkasi, dan integritas pribadi yang baik.

6) Akurat, artinya informasi tentang kinerja yang diawasi memiliki ketepatan data/informasi yang sangat tinggi.

7) Tepat waktu, artinya kata yang dihasilkan dapat digunakan sesuai dengan saat untuk melakukan perbaikan.

8) Objektif dan komprehensif.

9) Tidak mengakibatkan pemboroosan

10) Tindakan dan kegiatan pengawasan bertujuan untuk menyamankna rencana atau keputisan yang telah dibuat.

11) Kegiatan oengawasan harus mampu mengoreksi dan menilai pelaksanaan pekerjaan sesuai dengan rencana semula. ${ }^{14}$

\section{g) Rencana anggaran pendapatan belanja sekolah (RAPBS).}

RAPBS perlu memperhatikan asas anggaran berikut ini.

1) Asas kecermatan

2) Asas terperinci

3) Asas keseluruhan

4) Asas keterbukaan

5) Asas periodic

${ }^{14}$ Ibid, Hlm. 65-66 
6) Asas pembenaan

Masalah-masalah terkait dengan peyusunan RAPBS:

Salah satu implikasi dari penerapan Manajemen Berbasis Sekolah sebagaimana diamanatkan dalam perundang-undangan sistem pendidikan adalah diharuskannya pimpinan sekolah (terutama kepala sekolah) untuk mengemban tanggung jawab yang lebih besar dalam proses pengembangan RAPBS. Oleh karena itu, pimpinan itu disarankan menyadari berbagai masalah yang harus mereka hadapi untuk melaksanakan tangung jawab yang besar itu. berikut ini diuraikan beberapa masalah yang sering muncul dalam proses penyusunan RAPBS.

a. Anggaran diusulkan didasarkan uang yang tersedia dan tidak didukung pengetahuan yang memadai.

b. Kurang lengkapnya penjelasan tentang pentingnya usulan anggaran untuk meningkatkan belajar siswa.

c. Penurunan anggaran pendidikan dari tahun ke tahun.

d. Kurangnya kemampuan dalam mengevaluasi usulan anggaran.

e. Permintaan untuk membeli barang bermerek tertentu atau ancaman sentralisasi anggaran.

f. Kurangnya pembinaan, komunikasi, dan konsultasi dengan pihak-pihak terkait. ${ }^{15}$

Strategi penyusunan RAPBS (Rencana Anggaran Pnedapatan Belanja Sekolah):

a. Suatu pola keputusan yang integrity, coherent, dan menyatukan di antara setiap komponen.

b. Menentukan dan mengembangkan tujuan lembaga yang dinyatakan dalam sasaran jangka pendek, jangka oanajang, jangka menengah, program dan prioritas dari alokasi sumber-sumber daya pendidikan.

c. Memilih jenis kemampuan, keterampilan, pengetahuan apa saja yang mungkin akan diperlukan oleh masyarakat di masa yang akan datang.

d. Merespons dengan cepat semua peluang dan ancaman, kelemahan dan keunggulan yang ada di pihak lembaga pendidikan.

${ }^{15}$ Jamal Ma'mur Asmani, Tips Aplikasi Manajemen Sekolah, Diva Press, Yogyakarta,2010, hlm. 216-249 
e. Membangun komitmen dari semua pihak, siswa, orangtua, masyarakat, pemerintah, unit-unit Depdikbud sampai pada internal sekolah (kepala sekolah-siswa) untuk bersama-sama meningkatkan mutu sekolah.

f. Menentukan tingkat kontribusi dari setiap input pendidikan yang bermuatan biaya terhadap mutu pendidikna atau prestasi belajar siswa (efisiensi internal) dan angka permintaan masyarakat terhadap lulusan sekolah (efisiensi eksternal). ${ }^{16}$

\section{Critical Thinking}

Pendidikan nasional kita dihadapkan kepada masalah antara lain, peningkatan kualitas, pemerataan kesempatan, keterbatasan anggaran yang tersedia dan belum terpenuhi sumber dayadari masyarakat secara profesional sesuai dengan prinsip pendidikan sebagai tanggung jawab bersama antara pemerintah, masyarakat dan orang tua.

Dalam peningkatan kualitas manusia Indonesia, pemerintah tidak merupakan suatu sistem yang lepas dengan pihak swasta dan masyarakat. Hubungan pemerintah, masyarakat, dan swasta merupakan hubungan yang tidak terpisahkan dalam peranannya untuk meningkatkan pemerataan dan mutu pendidikan.

Jika kita menempatkan posisi pendidikan dalam mencerdaskan kehidupan bangsa dalam konteks masyarakat madani, diperlukan kebaranian investasi yang besar untuk memperkuat sistem pendidikan nasional. Di samping itu diperlukan juga adanya upaya yang sangat serius dalam memperkuat pendidikan sebagai jalan utama kekuatan dengan yang bukan saja sebagai peran konstitusional. Akan tetapi menjadi jawaban terhadap tantangan nyata perkembangan masyarakat dalam kondisi internal menjadi peraturan global.

Suatu penganggaran itu tidak hanya dianggarkan, tapi sebelumnya sudah ada planning agar semua anggaran yang ada sesuai dengan apa yang diagendakan, tapi tidak semua planning anggaran itu $100 \%$. Jadi, untuk menutupi kekurangan ituharus ada planning anggaran tak terduga. Dalam hal ini harus ada pemasukan yang dijadikan jalan keluar apabila anggaran awal melebihi target yang ada.

\footnotetext{
${ }^{16}$ Nanang Fattah, Op.Cit, Hlm. 53-55
} 


\section{KESIMPULAN}

A. Perencanaan Anggaran lembaga pendidikan adalah suatu rencana operasi dari suatu kegiatan atau proyek yang mengandung perincian pengeluaran biaya untuk suatu periode tertentu agar lembaga yang ada dapat dimanfaatkan secara optimal untuk menunjang tercapainya pendidikan.

B. Hal-hal yang terkait dengan perencanaan anggaran lembaga pendidikan yaitu:

a) Penyusunan anggaran

1. Merencanakan anggaran.

2. Mempersiapkan anggaran.

3. Mengelola pelaksanaan anggaran.

4. Menilai pelaksanaan anggaran

b) Proses anggaran belanja sekolah

\section{Comparative approach}

2. The planning programming budgeting evaluating system approach

\section{Function approach}

4. Termasuk dalam pendekatan ini adalah elemen-elemen yang terkandung dalam pendekatan comperative dan PPBES.

c) Karakteristik anggaran

Anggaran pada dasarnya terdiri dari dua sisi, yaitu sisi penerimaan dan sisi pengeluaran.

d) Fungsi anggaran

Sebagai alat untuk perencanaan dan pengendalian, juga merupakan alat bantu bagi manajemen dalam mengarahkan suatu lembaga menempatkan organisasi dalam posisi yang kuat dan lemah.

e) Prinsip-prinsip anggaran

Prinsip anggaran adalah bagaimana memanfaatkan dana secara efisisn, mengalokasikan secara tepat, sesuai dengan skala priorit.

f) Pengawasan anggaran

Pengawasan anggaran bertujuan untuk mengukur, membandingkan, menilai alokasi biaya dan tingkat penggunaannya.

g) Rencana anggaran pendapatan belanja sekolah (RAPBS)

RAPBS perlu memperhatikan asas anggaran berikut ini.

1) Asas kecermatan 
2) Asas terperinci

3) Asas keseluruhan

4) Asas keterbukaan

5) Asas periodic

6) Asas pembenaan 


\section{DAFTAR PUSTAKA}

Aziz, A., \& Saihu, S. (2019). Interpretasi Humanistik Kebahasaan: Upaya Kontekstualisasi Kaidah Bahasa Arab. Arabiyatuna: Jurnal Bahasa Arab, 3(2), 299-214

Dedi Supriadi, Satuan Biaya Pendidikan, PT. Remaja Rosdakarya, Bandung, 2004

E. Mulyasa, Manajemen berbasis sekolah, PT Remaja Rosdakarya, Bandung, Mei 2004

Fatah Syukur, Manajemen Pendidikan, PT. Pustaka Rizki Putra, Semarang, 2011

Jamal Ma'mur Asmani, Tips Aplikasi Manajemen Sekolah, Diva Press, Yogyakarta,2010

Mubin, F. (2019). TAFSIR EMANSIPATORIS: PEMBUMIAN METODOLOGI TAFSIR PEMBEBASAN. Mumtaz: Jurnal Studi Al-Quran dan Keislaman, 3(1), 131-151.

Mubin, F. KEADILAN DALAM GENDER: KAJIAN KEPEMIMPINAN WANITA DALAM ISLAM1,

Mubin, F. MODEL-MODEL PEMBELAJARAN BERBASIS MADRASAH DAN KEGIATAN LAIN YANG DIPERLUKAN DI DALAMNYA (FAKTOR PENDUKUNGNYA).

Nanang Fattah, "Ekonomi Dan Pembiayaan Pendidikan", Rosdakarya, Bandung, 2004

Nanang Fattah, Landasan Manajemen Pendidikan, PT Remaja Rosdakarya, Bandung, 1996

Ronaldo, R., Zulfikar, A., Saihu, Ismail, \& Wekke, I. S. (2020). International relations of the asia pacific in the age of trump. Journal of Environmental Treatment Techniques, 8(1), 244-246.

Şahin, C. RELIGIA.

Saihu, Aziz, A., Mubin, F., \& Sarnoto, A. Z. (2020). Design of islamic education based on local wisdom (An analysis of social learning theories in forming character through ngejot tradition in bali). International Journal of Advanced Science and Technology, 29(6), 12781293.

Saihu, M. (2019). Urgensi 'Urf dalam Tradisi Male dan Relevansinya dalam Dakwah Islam di Jembrana-Bali. Jurnal Bimas Islam, 12(1), 173-201.

Saihu, M. (2019). Merawat Pluralisme Merawat Indonesia (Potret Pendidikan Pluralisme Agama Di Jembrana-Bali). Deepublish.

Saihu, M. M., \& Aziz, A. (2020). Implementasi Metode Pendidikan Pluralisme Dalam Mata Pelajaran Pendidikan Agama Islam. Belajea; Jurnal Pendidikan Islam, 5(1), 131-150.

Saihu, S. (2019). IMPLEMENTASI MANAJEMEN BALANCED SCORECARD DI PONDOK PESANTREN JAM'IYYAH ISLAMIYYAH TANGERANG SELATAN. Mumtaz: Jurnal Studi Al-Quran dan Keislaman, 3(1), 1-22.

Saihu, S. (2019). KOMUNIKASI PENDIDIK TERHADAP ANAK BERKEBUTUHAN KHUSUS DI SEKOLAH KHUSUS ASY-SYIFA LARANGAN. Andragogi: Jurnal Pendidikan Islam dan Manajemen Pendidikan Islam, 1(3), 418-440.

Saihu, S. (2019). KONSEP MANUSIA DAN IMPLEMENTASINYA DALAM PERUMUSAN TUJUAN PENDIDIKAN ISLAM MENURUT MURTADHA MUTHAHHARI. Andragogi: Jurnal Pendidikan Islam dan Manajemen Pendidikan Islam, 1(2), 197-217.

Saihu, S. (2019). PENDIDIKAN KARAKTER BERBASIS KEARIFAN LOKAL (STUDI DI JEMBRANA BALI). Edukasi Islami: Jurnal Pendidikan Islam, 8(01), 69-90.

Saihu, S. (2019). Pendidikan Pluralisme Agama: Kajian tentang Integrasi Budaya dan Agama dalam Menyelesaikan Konflik Sosial Kontemporer. Jurnal Indo-Islamika, 9(1), 67-90, 
Saihu, S. (2019). RINTISAN PERADABAN PROFETIK UMAT MANUSIA MELALUI PERISTIWA TURUNNYA ADAM AS KE-DUNIA. Mumtaz: Jurnal Studi Al-Quran dan Keislaman, 3(2), 268-279,

Saihu, S. (2020). ETIKA MENUNTUT ILMU MENURUT KITAB TA'LIM MUTA'ALIM. $A l$ Amin: Jurnal Kajian Ilmu dan Budaya Islam, 3(1), 99-112.

Saihu, S. (2020). KONSEP PEMBAHARUAN PENDIDIKAN ISLAM MENURUT FAZLURRAHMAN. Andragogi: Jurnal Pendidikan Islam dan Manajemen Pendidikan Islam, 2(1), 82-95.

Saihu, S. (2020). Pendidikan sosial yang terkandung dalam Surat At-Taubah Ayat 7172. Edukasi Islami: Jurnal Pendidikan Islam, 9(01), 127-148.

Saihu, S. (2020). The Effect of Using Talking Stick Learning Model on Student Learning Outcomes in Islamic Primary School of Jamiatul Khair, Ciledug Tangerang. Tarbawi: Jurnal Keilmuan Manajemen Pendidikan, 6(01), 61-68.

Saihu, S., \& Mailana, A. (2019). Teori pendidikan behavioristik pembentukan karakter masyarakat muslim dalam tradisi Ngejot di Bali. Ta'dibuna: Jurnal Pendidikan Islam, 8(2), 163-176.

Saihu, S., \& Marsiti, M. (2019). PENDIDIKAN KARAKTER DALAM UPAYA MENANGKAL RADIKALISME DI SMA NEGERI 3 KOTA DEPOK, JAWA BARAT. Andragogi: Jurnal Pendidikan Islam dan Manajemen Pendidikan Islam, 1(1), 2354.

Saihu, S., \& Rohman, B. (2019). PEMBENTUKAN KARAKTER MELALUI MODEL PENDIDIKAN TRANSFROMATIFE LEARNING PADA SANTRI DI PONDOK PESANTREN NURUL IKHLAS BALI. Edukasi Islami: Jurnal Pendidikan Islam, 8(02), 435-452.

Saihu, S., \& Taufik, T. (2019). PERLINDUNGAN HUKUM BAGI GURU. Al Amin: Jurnal Kajian Ilmu dan Budaya Islam, 2(2), 105-116.

Udin Syaifudin, Sa'ud Dan Abin Syamsuddin Makmun. Perencanaan Pendidikan Suatu Pendekatan Komprensif, Bandung: PT Remaja Rosdakarya. 2007 